\title{
Dissecting The Value-Momentum Spread: Sector Allocation Effect Versus Country Allocation Effect
}

Heng-Hsing Hsieh, PhD, CFA, University of the Western Cape, South Africa Kathleen Hodnett, PhD, University of the Western Cape, South Africa

\begin{abstract}
Empirical literature suggests that sector allocation might be a more effective approach in gaining diverse exposures in the global equity market compared to country allocation due to the growing integration of economic activities amongst countries. In addition, sector allocation often provides unique exposures to a variety of investment styles. We undertake to investigate the relative importance of sector allocation versus country allocation in explaining the return differences between investment style indexes in the global equity market. After constructing the global value and momentum style indexes from global equities, we conduct performance attribution on the global value-momentum spread over the period from 01 January 1991 to 31 December 2008. The results show that both sector and country allocation effects explain the significant variations in the global value-momentum spread over the examination period. While the sector allocation effect explains $39.342 \%$ of the variations in the value-momentum spread, the country allocation effect only explains $10.444 \%$ of the variations. Our study results support the rising importance of sector allocation policy relative to country allocation policy in managing global equity style investments.
\end{abstract}

Keywords: Globalization; International Integration; International Diversification; Sector Allocation; Country Allocation; Value Investing; Momentum Investing

\section{INTRODUCTION}

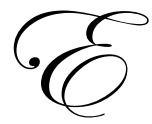

fficient market anomalies documented in empirical literature, such as the value effect, the momentum effect and the size effect, are pursued by active fund managers as the mainstream investment styles to distinguish their performance from their rivals. In order to exploit efficient market anomalies in the global equity market, the asset allocation universe needs to provide sufficient exposures to different dimensions of risk inherent in the global equity market. Cavaglia and Morez (2002) indicate that the traditional international asset allocation approach that overlays securities within countries is only effective when the integrations amongst countries remain weak. The increased integration in the global economic activities, as a result of globalization, implies that allocating assets into different sectors rather than different countries might be a more effective method of exploring different dimensions of risk in the global equity market. Vardharaj and Fabozzi (2007) further point out that sector and style allocations are inter-correlated as sectors tend to tilt towards certain investment styles at times. For example, during the information technology (I.T.) bubble, the price multiples of I.T. stocks outpaced the price multiples of stocks in all other sectors. The I.T. sector essentially represents the glamour investment style in the global equity market. Thus, neglecting the importance of sector allocation could lead to misrepresentation of an important investment style in asset allocation.

The objective of this research is to compare and contrast the effects of sector versus country allocation in distinguishing the performance of different investment styles. Our research focuses on the global value and momentum investment styles based on the value effect and momentum effect that are first documented by Basu (1977) and Jegadeesh and Titman (1993). We construct the global value and momentum style indexes from the global equity market over the period from 01 January 1991 to 31 December 2008. The return differences in the two 
global style indexes are calculated monthly as the global value-momentum spread. We adopt the return-based global performance attribution technique of Solnik and McLeavey (2003) to analyze the sources of the value-momentum spread based on the sector allocation approach and the country allocation approach respectively. To the authors' knowledge, at the time of writing, this paper is the first attempt to analyze the attributions of global equity style spreads using this approach. The cross-sectional return differences between the global value and momentum indexes are firstly decomposed into the currency allocation effect, the market allocation effect (by sector or by country) and the security selection effect in each month over the examination period. We then compute the percentages of the global value-momentum spread that are explained by the sector allocation effect and the country allocation effect separately using ordinary least squares regression. The test results provide insights to active fund managers on the relative importance of sector allocation versus country allocation in devising distinctive investment style strategies in the global equity market. While empirical studies related to this subject generally focus on the relative diversification benefits of country and sector allocations and their relative abilities in explaining global fund returns, this paper places emphasis on the relative contributions of sector and country allocations in explaining the return differences between the global equity style indexes.

\section{LITERATURE REVIEW}

Solnik (1974) investigates the pricing of risk in the global capital market. His empirical findings suggest that investors should pursue international diversification due to the moderate cross-country correlations between asset classes. This concept is challenged by recent empirical studies as the trade barriers are gradually removed among countries with growing tendency towards integration of cross-boarder economic activities. Baca, Garbe and Weiss (2000) employ time-series regressions to determine the strength of sector indexes in explaining the variations in country index returns and vice versa. A significant shift of explanatory power from country effect to sector effect is detected over the most recent 48 months in the examination period ending 31 March 1999. The comparison of the relative importance of sector versus country effects is also investigated by Cavaglia, Brightman and Aked (2000). They find evidence that diversification across sectors provides greater risk reduction than cross-boarder diversification. Cavaglia et al (2000) suggest that such phenomenon is expected to persist and even strengthen due to globalization. L'Her, Oumar and Tnani (2002) compare the relative importance of sector and country factor loadings in explaining global stock returns over the period from 01 January 1992 to 31 December 2000. They find that the portion of global stock returns attributable to country effects decline from $26.81 \%$ to only $7.85 \%$ while sector effect grows its explanatory power from $5.54 \%$ to $17.39 \%$ over the examination period. L'Her et al (2002) conclude that asset allocation decisions should be implemented to incorporate both country and sector dimensions to maximize the benefits of diversification.

Estrada, Kritzman and Mygren (2005) examine the risk-adjusted performance of portfolios formed based on industry allocation versus the performance of portfolios formed by country allocation in Europe over the period 1989 to 2003 . Test results reveal that country allocation approaches dominates the industry approach in the early 1990s, but this result reverses in the late 1990s. Estrada, et al (2005) argues that since European countries exhibit the most economic, fiscal, monetary and financial integration in the world, diversification within European countries have become ineffective. This argument is supported by tests conducted by Brooks and Del Negro (2005), who finds that cross-border diversification within Europe, delivers only half of the risk reduction from diversification globally. The growing importance of industry factors relative to country factors is also documented by Diermeier and Solnik (2001), Hopkins and Miller (2001), Capeci and Campollo (2002) and LaBarge (2008).

Phylaktis and Xia (2006) examine the role of the country and sector effects on international equity returns over the period from 1992 to 2001. Their results show that the growth of the sector effect varies across regions. More specifically, while the dominance of the sector effect is prominent in Europe and the United States of America, the country effect still dominates in Asia-Pacific and Latin America. Garff (2011) further investigates the relative importance of country and sector effects in the developed and the developing countries separately. Test results reveal that although the sector effect dominates in developed countries from 1999 to 2001 and again in 2007 and 2008, the country effect dominates the sector effect in developing countries in all time periods.

Based on the argument for growing sector influences in the global equity market, Cavaglia and Morez (2002) propose the use of the cross-industry, cross-country allocation (CICCA) approach for allocating assets in the 
global equity market. Strategies derived from the CICCA approach outperform their respective global benchmarks over the period from 1990 to 2001. Cavaglia and Morez (2002) further analyze the risk-adjusted performance of global portfolios sorted by country, global industry or on a bottom-up basis by regressing portfolio returns on the world, value, size and momentum factor-mimicking portfolio returns. The global industry portfolios are found to dominate all other portfolios on a risk-adjusted basis.

\section{RESEARCH METHODOLOGY}

In order to gain sufficient coverage of sector exposures in the research sample, the Dow Jones (DJ) Sector Titans Composite Index is employed as the research database. The DJ Sector Titans Composite Index is comprised of the largest 30 global stocks by U.S. dollar market capitalization from each of the 19 second tier Supersectors defined by the Industry Classification Benchmark (ICB). The sectors covered by this composite include automobiles and parts, banks, basic resources, chemicals, construction and materials, financial services, food and beverages, healthcare, industrial goods and services, insurance, media, oil and gas, personal and household goods, real estate, retail, technology, telecommunication, travel and leisure and utilities. The countries covered by this composite include Australia, Belgium, Brazil, Canada, Denmark, Spain, Finland, France, Germany, Greece, Hong Kong, Ireland, Italy, Japan, Korea, Luxembourg, Mexico, Netherlands, Norway, Portugal, South Africa, Sweden, Singapore, Switzerland, Taiwan, the United Kingdom and the United States of America. Monthly total return index, stock price, number of outstanding stocks, market capitalization, book value per share, earnings per share, dividend per share, sales per share and cash flow per share of the constituents of the DJ Sector Titans Composite Index over the period from 01 January 1990 to 31 December 2008 are downloaded from DataStream International as of 30 June 2010. All attribute data are subsequently converted into U.S. dollars. Due to the fact that DataStream International only records data as the information become publicly available without subsequently replacing data recorded when new data arrives, this database is not subject to look-ahead bias. Based on the argument that large firms are less likely to be non-survivors, the global value and momentum indexes are only constructed from the top 300 stocks in terms of the U.S. dollar market capitalization in each month.

Adopting the style index construction methodology outlined in Hsieh (2010), the research begins with the construction of the equally-weighted global value and momentum indexes over the period from 1 January 1991 to 31 December 2008. The global value index is constructed using the top 50 stocks in terms of the average value of the five value-based matrices, namely book value-to-market ratio, earnings yield, dividend yield, sales-to-price ratio and cash flow-to-price ratio. On the other hand, the global momentum index is constructed using the top 50 stocks in terms of the prior 12-month return computed from the U.S. dollar total return index that incorporates both capital gains and dividend yield. The global value and momentum indexes are rebalanced at the beginning of each month in the examination period with equal weights allocated to the index constituents. Adopting the return-based global performance attribution approach of Solnik and McLeavey (2003) cited in Hsieh (2010), the monthly dollar return $\left(r_{(D) t}\right)$ differences between the value index $V$ and momentum index $M$ (that is, the value-momentum spread) are decomposed into the currency allocation effect, the market allocation effect (by sector or by country) and the security selection effect based on the cross-sectional regression shown in Equation 1:

$$
\begin{aligned}
& r_{(D) V, t}-r_{(D) M, t}=\sum_{j=1}^{N}\left(\phi_{j, V, t}-\phi_{j, M, t}\right)+\sum_{j=1}^{N}\left(\psi_{j, V, t}-\psi_{j, M, t}\right)+\sum_{j=1}^{N}\left(\eta_{j, V, t}-\eta_{j, M, t}\right) \\
& \sum_{j=1}^{N}\left(\phi_{j, V, t}-\phi_{j, M, t}\right), \sum_{j=1}^{N}\left(\psi_{j, V, t}-\psi_{j, M, t}\right) \text { and } \sum_{j=1}^{N}\left(\eta_{j, V, t}-\eta_{j, M, t}\right) \text { represent the currency allocation effect, the }
\end{aligned}
$$

market allocation effect (by sector or by country) and the security selection effect that contribute to the return difference between value index $V$ and the momentum index $M$ in month $t$.

The specifications of the currency allocation effect, the sector/country allocation effect and the security selection effect are depicted by Equation 2, Equation 3 and Equation 4 respectively. The decomposition method of Solnik and McLeavey (2003) is also adopted by Hsieh (2010) to analyze the global momentum-size spread and the global value-size spread. 
$\sum_{j=1}^{N}\left(\phi_{j, V, t}-\phi_{j, M, t}\right):$ Currency Allocation Effect

Where:

$\phi_{j, V, t}=\sum_{i=1}^{n_{j, t}}\left(w_{i, j, V, t} \times\left(r_{(D) i, j, t}-r_{(F) i, j, t}\right)\right)$, is the portion of value index $V$ 's domestic currency return attributable to currency conversion in month $t$;

$\phi_{j, M, t}=\sum_{i=1}^{n_{j, t}}\left(w_{i, j, M, t} \times\left(r_{(D) i, j, t}-r_{(F) i, j, t}\right)\right)$, is the portion of momentum index $M$ 's domestic currency return attributable to currency conversion in month $t$;

$w_{i, j, V, t} \quad$ is the weight of the $i$ th stock from the $j$ th sector/country in the value index $V$ in month $t$;

$w_{i, j, M, t} \quad$ is the weight of the $i$ th stock from the $j$ th sector/country in momentum index $M$ in month $t$;

$r_{(D) i, j, t} \quad$ is the domestic currency return on the $i$ th stock from the $j$ th sector/country in month $t$;

$r_{(F) i, j, t} \quad$ is the foreign currency return on the $i$ th stock from the $j$ th sector/country in month $t$; and

$n_{j, t} \quad$ is the number of stocks in the $j$ th sector/country in month $t$.

$\sum_{j=1}^{N}\left(\psi_{j, V, t}-\psi_{j, M, t}\right):$ Sector/Country Allocation Effect

Where:

$\psi_{j, V, t}=\sum_{i=1}^{n_{j, t}} w_{i, j, V, t} \times \sum_{i=1}^{n_{j, t}}\left(w_{i, j, M, t} \times r_{(F) i, j, t}\right)$, is the portion of value index $V$ 's domestic currency return generated from its sector/country allocation policy in month $t$; and

$\psi_{j, M, t}=\sum_{i=1}^{n_{j, t}} w_{i, j, M, t} \times \sum_{i=1}^{n_{j, t}}\left(w_{i, j, M, t} \times r_{(F) i, j, t}\right)$, is the portion of momentum index $M$ 's domestic currency return generated from its sector/country allocation policy in month $t$.

$\sum_{j=1}^{N}\left(\eta_{j, V, t}-\eta_{j, M, t}\right):$ Security Selection Effect

Where:

$\eta_{j, V, t} \quad=\sum_{i=1}^{n_{j, t}} w_{i, j, V, t} \times \sum_{i=1}^{n_{j, t}}\left(w_{i, j, V, t} \times r_{(F) i, j, t}\right)$, is the contribution of the stocks selected by the value index $V$ to the domestic currency return of the value index $V$ in month $t$; and

$\eta_{j, M, t}=\sum_{i=1}^{n_{j, t}} w_{i, j, V, t} \times \sum_{i=1}^{n_{j, t}}\left(w_{i, j, M, t} \times r_{(F) i, j, t}\right)$, is the contribution of the stocks selected by the momentum index $M$ to the domestic currency return of the momentum index $M$ in month $t$;

The sector allocation effect and the country allocation effect are dealt with separately in the analysis using two separate factor models based on Equation 1. Holding the currency allocation effect constant, the remaining difference in returns between the value and the momentum indexes is shared by the sector allocation effect and the security selection effect, or alternatively the country allocation effect and the security selection effect. Thus, the greater the ability of the country or sector allocation in explaining the return difference, the less is the remaining return difference to be explained by the security selection effect. Once the monthly value-momentum spread is decomposed over the examination period, we regress the monthly value-momentum spread on the monthly sector/country allocation effect to determine the percentage of the value-momentum spread that is explained by the sector/country allocation effect using time-series regression shown in Equation 5: 
$r_{(D) V, t}-r_{(D) M, t}=\alpha+b \times \psi_{t}+e_{t}$

The $R$-squared of the regression indicates the percentage of the value momentum spread that is explained by the sector/country allocation effect over the examination period. Thus, the relative importance of sector versus country allocation in driving the value-momentum spread can be determined. To draw comparison between the distinctive performance characteristics of the global value and momentum investment styles, the risk-adjusted performance measures of the value and momentum indexes are computed based on the Sharpe ratio, the Treynor measure and Jensen's alpha. Using the 3-month U.S. Treasury bill as the risk-free proxy, the Sharpe Ratio of value/momentum index $X$ is computed in Equation (6):

Sharpe $_{X}=\frac{R_{X}-R_{f}}{\sigma_{X}}$

Where:

$R_{X} \quad$ is the return on the value/momentum index $X$;

$R_{f} \quad$ is the yield on the 3-month U.S. Treasury bill; and

$\sigma_{X} \quad$ is the standard deviation of return on the value/momentum index $X$.

The Sharpe ratio measures the reward for bearing total risk (measured by the standard deviation of returns). The relevant risk measure in the Treynor measure and Jensen's alpha is systematic risk measured by the beta coefficient of the time-series regression in Equation 7, using the Morgan Stanley Capital International (MSCI) World Index as the market proxy:

$R_{X, t}-R_{f, t}=\alpha_{X}+\beta_{X} \times\left(R_{m, t}-R_{f, t}\right)+\varepsilon_{X, t}$

Where:

$R_{X, t} \quad$ is the return on the value/momentum index $X$ in month $t$;

$R_{f, t} \quad$ is the return on the 3-month U.S. Treasury bill in month $t$;

$R_{m, t} \quad$ is the U.S. dollar total return on the MSCI World Index in month $t$;

$\beta_{X} \quad$ is the beta coefficient of the regression; and

$\varepsilon_{X, t} \quad$ is the regression residual in month $t$.

The regression intercept $\alpha_{X}$ is Jensen's alpha that measures the abnormal return earned in excess of the required risk-adjusted return implied by the capital asset pricing model. The Treynor ratio, measuring the reward for bearing systematic risk, can be computed using Equation 8:

Treynor $_{X}=\frac{R_{X}-R_{f}}{\beta_{X}}$

\section{EMPIRICAL FINDINGS}

The performance statistics of the market proxy (MSCI World) and the global value and momentum indexes are displayed in Table 1. The global value index earns higher return over the examination period with lower standard deviation compared to the global momentum index. When risk is measured by the beta coefficient, the global value index seems to be much riskier compared to the global momentum index. Overall, the global value index outperforms the global momentum index in terms of risk-adjusted returns. Both of the global value and momentum indexes outperform the market proxy on a risk-adjusted basis. 
Table 1: Performance Statistics of the Global Style Indexes (1991 -2008)

\begin{tabular}{|lccc|} 
& MSCI World & Value Index & $\underline{\text { Momentum Index }}$ \\
\cline { 2 - 3 } Annualized Return & $7.26 \%$ & $16.73 \%$ & $15.72 \%$ \\
Annualized Standard Deviation & $14.69 \%$ & $16.80 \%$ & $17.77 \%$ \\
Beta Coefficient & 1.000 & 1.021 & 0.952 \\
& & & $59.99 \%$ \\
Sharpe Ratio & $14.98 \%$ & $69.46 \%$ & 0.112 \\
Treynor Ratio & 0.022 & 0.114 & $8.62 \%$ \\
Jensen's Alpha & $0.00 \%$ & $9.39 \%$ & \\
\hline
\end{tabular}

The log cumulative returns of the market proxy, the global value and momentum indexes and the global value-momentum spread over the evaluation period are displayed in Figure 1. A similar presentation of the interaction between various style indexes in relation to the global economic cycle is also documented by Hsieh (2010). The consistent outperformance of the global value and momentum indexes provide support to value and momentum investment strategies in the global equity market. It is noted that the global momentum index outperforms the global value index prior to the crash of the I.T. bubble in 2000. The global momentum index subsequently loses all its prior excess gain after 2000. The downward correction of the global momentum index is highlighted in the circled area on the cumulative value-momentum spread. This provides support to the argument of Vardharaj and Fabozzi (2007) that sector and style allocations are inter-correlated as sectors tend to tilt towards certain investment styles at times.

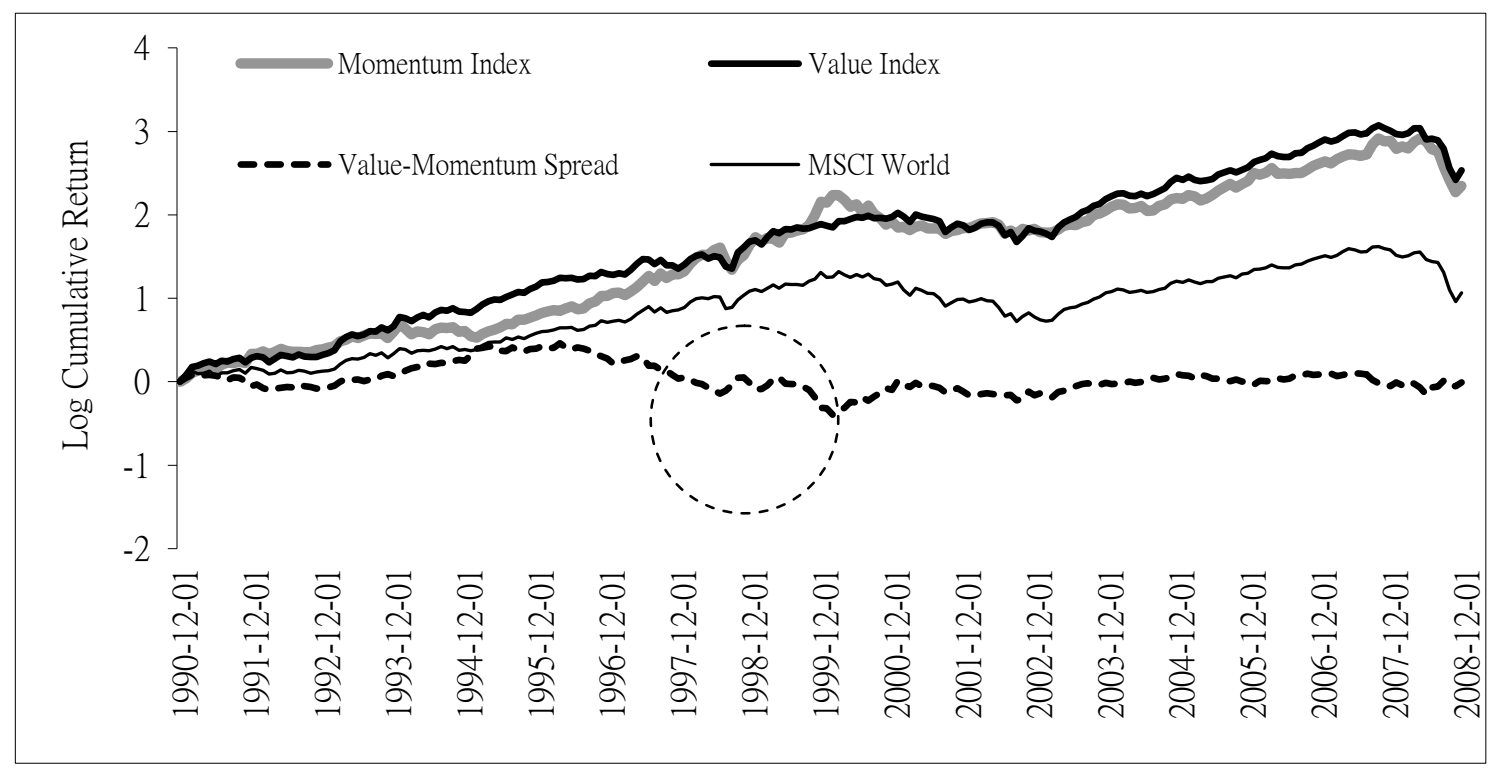

Figure 1: Cumulative Style Index Performance (1991 - 2008)

The comparison of the sector allocations and country allocations between the global value and momentum indexes are demonstrated in Figure 3 and Figure 4 respectively. Analyzing the sector allocations shown in Figure 2 indicates that the global value index overweighs the automobile and parts, banks, industrial goods and services, insurance, real estate, telecommunication and utilities sectors. On the other hand, the global momentum index places higher weights in the basic resources, chemicals, financial services, food and beverages, health care, media, retail and the technology sectors. The most distinctive differences in terms of sector allocation between the global value and momentum indexes is that the global value index heavily weighs the automobiles and parts and the banking sectors compared to the global momentum index. On the other hand, the global momentum index allocates relatively considerable amounts of capital into the health care, retail and the technology sectors. 


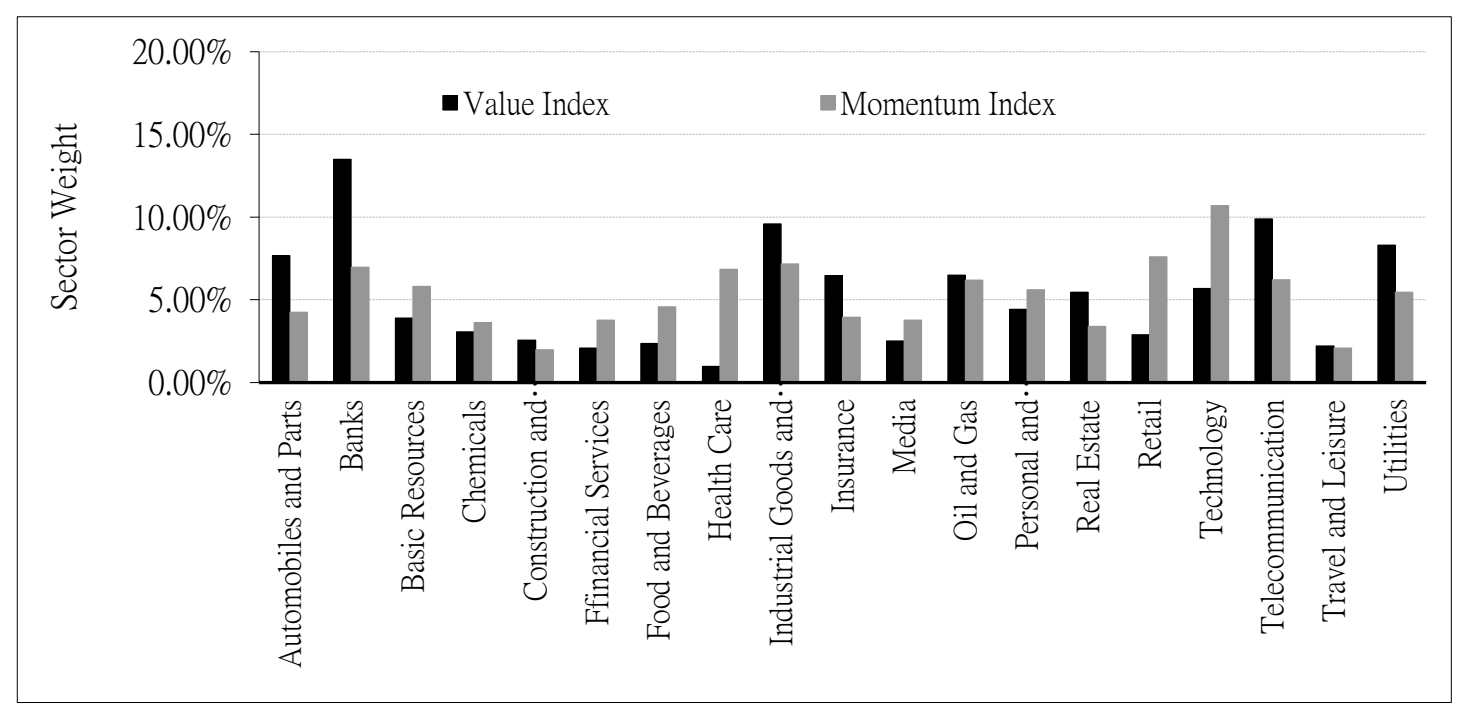

Figure 2: Sector Allocations of Global Style Indexes (1991 - 2008)

In terms of the country allocation decisions, Japan and the United States receive the majority of the capital allocations from both the global value and the momentum indexes. While the global value index allocates most of its capital to Japan (27.58\% compared to $11.75 \%$ for the global momentum index), the global momentum index allocates a significant $43.53 \%$ of its capital to the United States (compared to $20.04 \%$ for the global value index). A distinctive difference between the country allocations between the two style indexes is that the global value index only invests $0.88 \%$ of its capital to the United Kingdom compared to a significant $10.79 \%$ for the global momentum index.

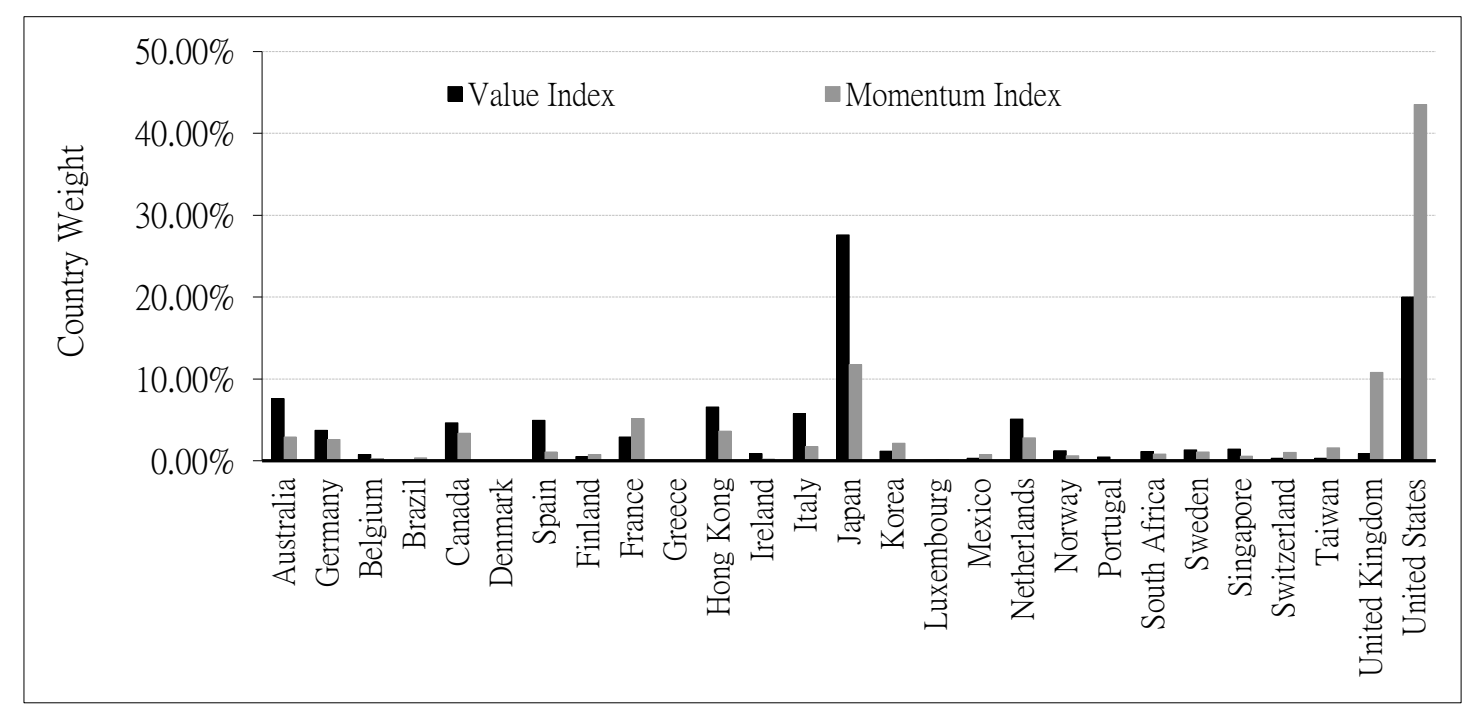

Figure 3: Country Allocations of Global Style Indexes (1991 - 2008)

The results of the performance attribution analysis on the global value-momentum spread based on sector allocation and country allocation over the examination period are displayed in Table 2 . The average monthly global value-momentum spread of $0.073 \%$ is computed as the average monthly return on the global value index (1.297\%) minus the average monthly return on the global momentum index $(1.224 \%)$. The average monthly global value- 
momentum spread of $0.073 \%$ is further decomposed into $-0.054 \%$ from the currency allocation effect, $-0.299 \%$ from the sector allocation effect and $0.426 \%$ from the security selection effect based on the sector allocation approach. Based on the country allocation approach, the global value-momentum spread is decomposed into $-0.054 \%$ from the currency allocation effect, $-0.147 \%$ from the country allocation effect and $0.273 \%$ from the security selection effect. This result shows that the global value index underperforms the global momentum indexes in terms of the currency allocation policy, the sector allocation policy and the country allocation policy. The excess return of the global value index over the global momentum index comes from the security selection effect.

Table 2: Value-Momentum Spread Attribution (1991 -2008)

Avg. Monthly Return (Value Index):

Avg. Monthly Return (Momentum Index):

Value-Momentum Spread:

Currency Allocation Effect

Sector/Country Allocation Effect

Security Selection Effect

Total Effect (Sum of Effects)

\section{$1.297 \%$ \\ $1.224 \%$ \\ $0.073 \%$}

Country Allocation

$-0.054 \%$

$-0.147 \%$

$0.273 \%$

$0.073 \%$

Table 3 demonstrates the regression results based on Equation 5, which provides direct comparison of the power of the sector allocation effect to the country allocation effect in explaining the global value-momentum spread. The $t$-statistics are shown in parenthesis for the regression coefficients. The $R$-squared of the regressions indicate that sector allocation policy is far more important than country allocation policy in distinguishing the value and momentum style returns. The sector allocation effect explains $39.342 \%$ of the global value-momentum spread compared to $10.444 \%$ of the spread being explained by the country allocation effect. The regression coefficients show that both sector allocation policy and country allocation policy influences the variations in the global valuemomentum spread positively. This implies that the average global value-momentum spread could have been much wider if the global value index did not underperform the global momentum index in terms of its sector and country allocation policies by such considerable extent $(-0.299 \%$ and $-0.147 \%$ for the sector and country allocation effects respectively). Overall, both sector allocation and country allocation contributes significantly in distinguishing the value and momentum investment styles in the global equity market since the $t$-statistics for the regression coefficients are significant at a $5 \%$ level.

Table 3: Influences of Sector and Country Allocations in the Value-Momentum Spread (1991 - 2008)

\begin{tabular}{|lcc|}
\hline & Sector Allocation & Country Allocation \\
R Squared & $39.342 \%$ & $10.444 \%$ \\
Intercept & 0.003 & 0.001 \\
& {$[1.6212]$} & {$[0.581]$} \\
B-Coefficient & 0.892 & 0.508 \\
& {$[11.781]$} & {$[4.996]$} \\
\hline
\end{tabular}

\section{CONCLUSION}

The analysis of sector allocation and country allocation reveal that the global value index and the global momentum index have distinguishable allocation preferences amongst sectors and countries. While the automobiles and parts and the banking sector are the favorite sectors for the global value index, the global momentum index prefers to allocate capital into the health care, retail and the technology sectors. While both the global value and momentum indexes invest considerable capital in Japan and the United States of America, the global momentum index invests heavily in the United Kingdom compared to the decimal U.K. capital allocation for the global value index. The fact that both the global value and momentum indexes outperform the MSCI World Index on a risk- 
adjusted basis over the examination period suggests that style anomalies do exist in the global equity market. The distinguishable performance between the global value and momentum indexes is also noted for the drift and correction of the performance for the global momentum index before and after the crash of the I.T. bubble in 2000. The growing importance of sector allocation over country allocation in the global equity market gains significant support from the regression analysis. The sector allocation effect explains nearly $40 \%$ of the variations in the global value-momentum spread compared to just over $10 \%$ explained by the country allocation effect. The coefficients of the regressions for both the sector allocation effect and the country allocation effect are significant at the 5\% level, which indicates that the return differences between the global momentum and value indexes are driven by both the sector allocation effect and the country allocation effect.

In conclusion, we recommend the application of sector allocation over country allocation in exploring diverse style exposures in the global equity market. In line with empirical literature, our research findings suggest that country allocation becomes a less effective method of global asset allocation in terms of exploring new investment opportunities and diversification due to the growing integration of cross-border economic activities. Investigations on the global performance attribution of other style spreads in the global equity market based on empirical efficient market anomalies are suggested as areas for further research.

\section{ACKNOWLEDGEMENT}

This research is supported by the National Research Foundation (NRF) of South Africa. We acknowledge the Research Office of the University of the Western Cape for their support. In addition, we thank Professor Paul van Rensburg from the University of Cape Town for his valuable comments and suggestions.

\section{AUTHOR INFORMATION}

Dr. Heng-Hsing Hsieh, CFA is the Head of Finance in the School of Business and Finance at the University of the Western Cape, South Africa. He is a CFA charterholder and a member of the South African Institute of Financial Markets (SAIFM). E-mail: ahsieh@uwc.ac.za. Corresponding Author.

Dr. Kathleen Hodnett is currently a Research Fellow (funded by the National Research Foundation (NRF) of South Africa) in the School of Business and Finance at the University of the Western Cape, South Africa. She is a member of the International Institute of Forecasters (IIF) and an associate member of the South African Institute of Financial Markets (SAIFM).

\section{REFERENCES}

1. Baca S P, Garbe B L and Weiss R A (2000), "The Rise of Sector Effects in Major Equity Markets", Financial Analysts Journal, vol. 56, no 5, 34-40.

2. Basu S (1977), "The Investment Performance of Common Stocks in Relation to Their Price to Earnings Ratio: A Test of the Efficient Markets Hypothesis", Journal of Finance, vol. 32, no 3, 663-682.

3. Brooks R and Del Negro M (2005), "Country versus Region Effects in International Stock Returns", The Journal of Portfolio Management, Summer, vol. 31, no 4, 67-72.

4. Capeci J and Campillo M (2002), "Growing Sector Momentum in Emerging Markets", Arrowstreet Capital, L.P.

5. Cavaglia S, Brightman C and Aked M (2000), “The Increasing Importance of Industry Factors”, Financial Analysts Journal, vol. 56, no 5,41-54.

6. Cavaglia S and Morez V (2002), "Cross-Industry, Cross-Country Allocation”, Financial Analyst Journal, vol. 58, no 6, 78-97.

7. Diermeier J and Solnik B (2001), "Global Pricing of Equity”, Financial Analysts Journal, vol. 57, no 4, 3747. 
8. $\quad$ Estrada J, Kritzman M, Myrgren S and Page S (2005), “Countries versus Industries in Europe: A Normative Portfolio Approach", Journal of Asset Management, vol. 6, no 2, 85-103.

9. Garff D J (2011), “Global Equity Investing: Do Countries Still Matter?”, February, Accuvest Global Advisors.

10. Hodnett K (2010), “Analysis of the Cross-Section of Equity Returns on the JSE Securities Exchange based on Linear and Nonlinear Modeling Techniques", Unpublished Doctoral Thesis, University of Cape Town.

11. Hopkins P and Miller H (2001), "Country, Sector, and Company Factors in Global Equity Portfolios", The Research Foundation of AIMR, Charlottesville.

12. Hsieh H (2010), "Applications of Global Equity Style Indices in Active and Passive Portfolio Management", Unpublished Doctoral Thesis, University of Cape Town.

13. Jegadeesh N and Titman S (1993), "Returns to Buying Winners and Selling Losers: Implications for Stock Market Efficiency", Journal of Finance, vol. 48, no 1, 65-91.

14. LaBarge K P (2008), "Diversification by Country and Global Sector: Considerations for Portfolio Construction", Vanguard Investment Counseling and Research.

15. L'Her J F, Sy O and Tnani M Y (2002), "Country, Industry, and Risk Factor Loadings in Portfolio Management", The Journal of Portfolio Management, Summer, 70-89.

16. Phylaktis K and Xia L (2006), "The changing Roles of Industry and Country Effects in the Global Equity Markets", The European Journal of Finance, December, vol. 12, no 8, 627-648.

17. Solnik B and McLeavey D (2003), International Investments, Revised International Edition, Pearson Education.

18. Vardharaj R and Fabozzi F J (2007), "Sector, Style, Region: Explaining Stock Allocation Performance", Financial Analysts Journal, vol. 63, no 3, 59-70. 